\title{
Airborne geophysical mapping as an innovative methodology for landslide investigation: evaluation of results from the Gschliefgraben landslide, Austria
}

\author{
R. Supper, I. Baroň, D. Ottowitz, K. Motschka, S. Gruber, E. Winkler, B. Jochum, and A. Römer \\ Geologische Bundesanstalt, Neulinggasse 38, 1030 Wien, Austria
}

Correspondence to: R. Supper (robert.supper@geologie.ac.at)

Received: 12 March 2013 - Published in Nat. Hazards Earth Syst. Sci. Discuss.: 28 May 2013

Revised: 5 November 2013 - Accepted: 18 November 2013 - Published: 17 December 2013

\begin{abstract}
In September 2009, a complex airborne geophysical survey was performed in the large landslide affected area of the Gschliefgraben valley, Upper Austria, in order to evaluate the applicability of this method for landslide detection and mapping. An evaluation of the results, including different remote-sensing and ground-based methods, proved that airborne geophysics, especially the airborne electromagnetic method, has a high potential for landslide investigation. This is due to its sensitivity to fluid and clay content and porosity, which are parameters showing characteristic values in landslide prone structures. Resistivity distributions in different depth levels as well as depth slices along selected profiles are presented and compared with ground geoelectrical profiles for the test area of Gschliefgraben.

Further interesting results can be derived from the radiometric survey, whereas the naturally occurring radioisotopes ${ }^{40} \mathrm{~K}$ and ${ }^{232} \mathrm{Th}$, as well as the man-made nuclide ${ }^{137} \mathrm{Cs}$ have been considered. While the content of potassium and thorium in the shallow subsurface layer is expressively related to the lithological composition, the distribution of caesium is mainly determined by mass wasting processes.
\end{abstract}

\section{Introduction}

Within the last decades, airborne geophysical surveys have been intensively applied for exploration of raw materials and groundwater exploration (e.g. IAEA-TECDOC-1363, 2003; Thomson et al., 2007; Gondwe et al., 2012). The big advantage of the application of airborne geophysics compared to other remote-sensing or ground-based methods is that multi-sensor, area wide information on subsurface parameters, down to several tens of metres of depth can be collected within a comparably short period of time. Due to significant technological improvements in the areas of hardware and software within the last 5-10 yr, airborne geophysics has recently developed into a promising approach for landslide investigation and rapid mapping (e.g. Sasaki and Nakazato, 2004. Nakazato and Konishi, 2005; Nakazato et al., 2006; Supper et al., 2008; Pfaffhuber et al., 2010; Tofani et al., 2013). However, due to the rough topography usually encountered in landslide susceptible areas, performing a high quality, multi-parameter airborne survey within the limits of usual research budgets still poses a big challenge to geophysicists.

Within the SafeLand project, which was funded by the Seventh Framework Programme for research and technological development (FP7) of the European Commission, several test studies were conducted to compare and evaluate the capabilities of different airborne and ground-based mapping and monitoring methods.

The Gschliefgraben area (Fig. 1), which comprises the most prominent recent landslide of Austria, was selected as one of the test sites to advance interpretation capabilities of airborne geophysics in general and to evaluate the usability of this approach for fast detection and mapping of landslides.

The complementary remote-sensing part of the investigations, conducted at this test site, consisted of a detailed morphostructural and morpho-dynamical analysis of the mass movement (landslide inventory), based on several high-resolution airborne laser scans. 


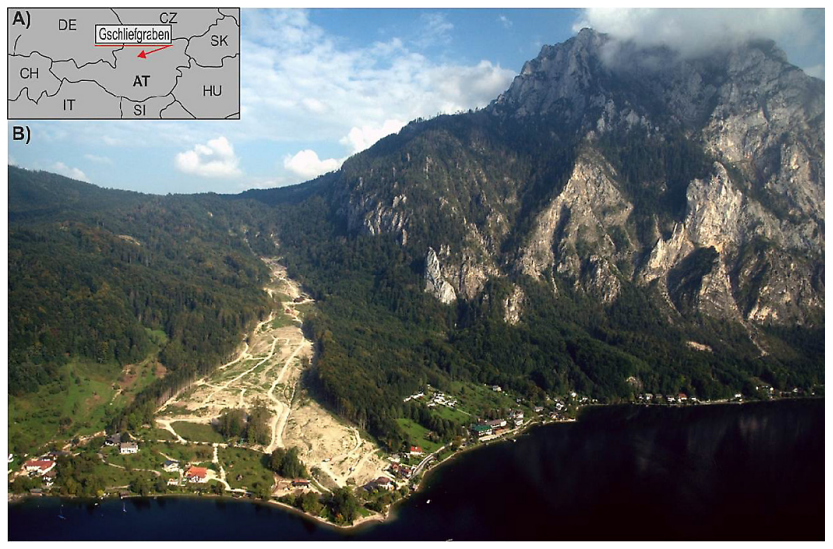

Fig. 1. General setting of the Gschliefgraben site: (A) Position within Austria, (B) Airborne photo of the Gschliefgraben valley and Mt. Traunstein from the west (Photo by: R. Supper, 2009).

\section{Airborne geophysical techniques}

The airborne geophysical system, operated by the Geological Survey of Austria (Motschka, 2001), incorporates several different airborne geophysical techniques:

- a frequency-domain electromagnetic system,

- a Cs-magnetometer,

- a gamma ray spectrometer and

- a passive microwave soil moisture sensor.

All parameters, coming from the different sensors, are recorded simultaneously during an airborne geophysical campaign. The actual position of each of the sensors is determined by several precise differential GPS sensors with base station correction and a laser and a radar altimeter. Furthermore, the flight path is recorded by a digital camera and some additional parameters (e.g. air temperature, sensor temperature, dew point) are recorded for applying necessary data corrections. Table 1 gives an overview of the different components of the airborne system.

\subsection{Airborne electromagnetics}

The airborne electromagnetic method (AEM) determines the distribution of the specific electrical resistivity within the subsurface and ultimately provides resistivity depth sections of the subsurface by applying delicate data inversion algorithms. The specific electrical resistivity is a physical property of the subsurface. Under the assumption of a nonconductive rock matrix, this parameter is mainly related to porosity, fluid and clay content and thus low values may act as an indicator for weakness zones and destabilized and partly saturated landslide bodies.

\subsubsection{The measurement principle}

In general, two different airborne electromagnetic techniques exist: the frequency domain (FDEM) and the time domain (TDEM) technique. The Austrian airborne system incorporates the frequency domain electromagnetic method.

The main part of a frequency domain electromagnetic system consists of a probe (also called "bird") of several metres in length, which is towed on a cable $30 \mathrm{~m}$ below a helicopter (Fig. 2). Inside the probe, there are several transmitting coils as well as receiving coils in different geometric arrangements (co-axial, co-planar loops). The transmitting coils generate an electromagnetic alternating field with certain frequencies (e.g. of $340 \mathrm{~Hz}, 3200 \mathrm{~Hz}, 7190 \mathrm{~Hz}$ and $28850 \mathrm{~Hz}$ in the case of the Austrian system). This primary field induces eddy currents inside conductive subsurface layers. In turn the corresponding (secondary) magnetic field generated by these currents induces a current in the receiver coils. Based on the amplitude and the phase shift of the secondary field relatively to the primary field, conclusions can be drawn on the electrical resistivity of the subsurface (Avdeev et al., 1998; Seiberl et al., 1998; Sengpiel and Siemon, 1998; Winkler et al., 2003; EM1DFM, 2000).

\subsubsection{Investigation depth}

The investigation depth of the FDEM method, in general between 30 and $100 \mathrm{~m}$, depends on the applied frequencies, geometric arrangements and the resistivity structure of the subsurface. Lower frequencies (e.g. $340 \mathrm{~Hz}$ ) have a larger penetration than high frequencies. By applying different frequencies at the same time, a sounding of the subsurface can be performed. However, the maximum penetration also depends on the resistivity structure. In case of a low resistive overburden, e.g. as it is in case of clay layers $(5-10 \mathrm{Ohmm})$, the investigation depth is limited to around $35 \mathrm{~m}$.

\subsection{Airborne gamma ray spectroscopy}

Airborne gamma-ray spectroscopy determines the natural and artificial radioactivity, which depends on the content of radioactive minerals within the first decimetres of the subsurface. Potassium, uranium and thorium are the only naturally occurring elements with radioactive isotopes of sufficient gamma-ray energy and intensity to be measured at airborne survey heights (Minty et al., 1997). The detected natural radiation is essentially caused by the decay of three unstable isotopes, which occur as fixed proportions of the total potassium, uranium and thorium content of surface rocks/soils: ${ }^{232} \mathrm{Th}$ (energy peak: $2.62 \mathrm{MeV}$ ), ${ }^{238} \mathrm{U}$ (energy peak: $1.76 \mathrm{MeV}$ ) and ${ }^{40} \mathrm{~K}$ (energy peak: $1.46 \mathrm{MeV}$ ).

With $2.33 \%$ in weight, potassium is one of the major elements of the Earth's upper crust. Potassium occurs mainly in alkali-feldspars and micas in felsic rocks as well as in clays as their weathering products (e.g. Illite). It has only a low 
Table 1. Comparison of the different components of the airborne system.

\begin{tabular}{llll}
\hline Method & Parameter & $\begin{array}{l}\text { Investigation } \\
\text { depth* }\end{array}$ & $\begin{array}{l}\text { Application for } \\
\text { mass movements }\end{array}$ \\
\hline Electromagnetics & $\begin{array}{l}\text { Subsurface resistivity } \rightarrow \text { depends on } \\
\text { porosity/saturation and clay content } \\
\text { Kamma ray }\end{array}$ & $0-70 \mathrm{~m}, \mathrm{Th},{ }^{137} \mathrm{Cs}$ content & $\begin{array}{l}\text { structural mapping of depth structure, } \\
\text { detection of landslide prone areas } \\
\text { mapping of composition of top layer, } \\
\text { reconstructing source area, detection of } \\
\text { Magnetics }\end{array}$ \\
$\begin{array}{l}\text { Passive microwave } \\
\text { Magnetic susceptibility of subsurface }\end{array}$ & $\begin{array}{l}\text { soil humidity } \\
\text { several kments }\left({ }^{137} \mathrm{Cs}\right)\end{array}$ & $\begin{array}{l}\text { no known application } \\
\text { spatial distribution of soil humidity } \\
\text { of top layer }\end{array}$ \\
\hline
\end{tabular}

* The effective investigation depth depends on the respective subsurface parameters.

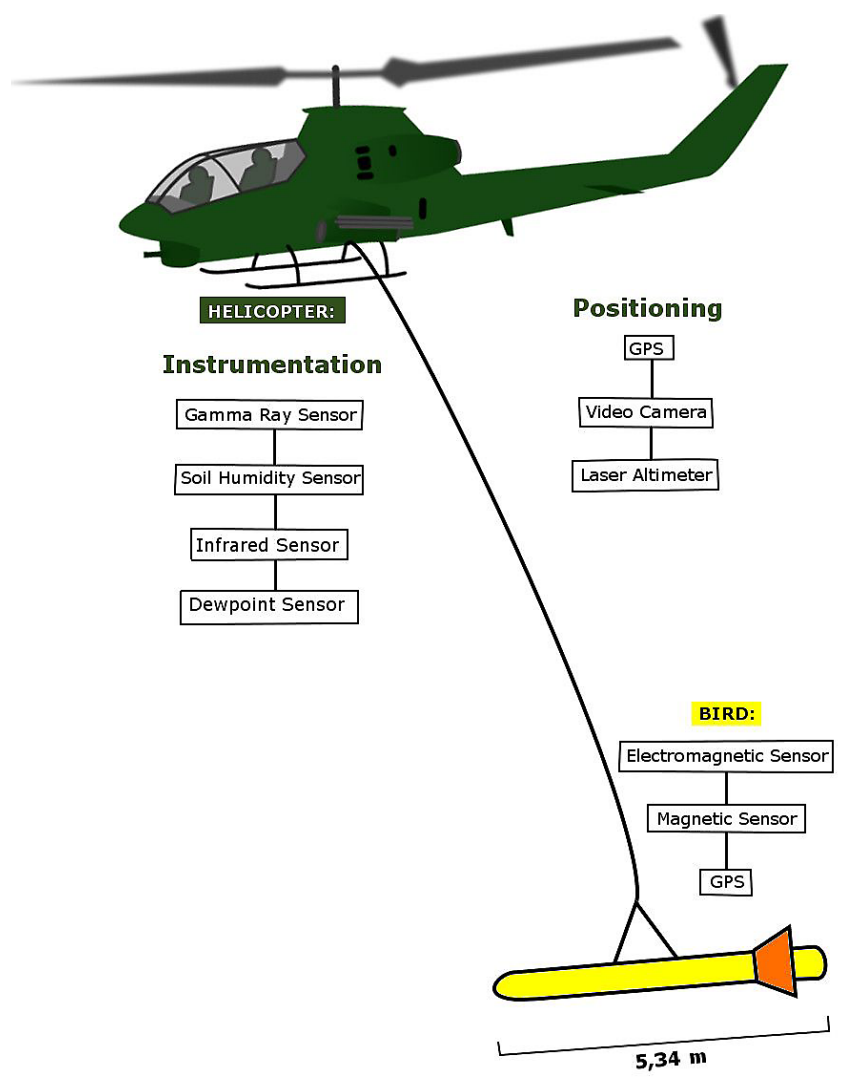

Fig. 2. Components of the Austrian airborne system.

content in mafic rocks (basalt) and a very low content in ultramafic rocks (dunite, peridotite). The maximum values were found at around $5 \%$ in granites and mudstones.

Thorium and uranium have a lithophile character and are therefore present as trace elements in most silicate rich rocks and in accessory minerals. The high charge and radius of the $\mathrm{Th}^{+4}$ and $\mathrm{U}^{+4}$ ions excludes them in the substitution of major ions in the crystallization of early rock forming minerals (IAEA-TECDOC-1363, 2003). In the magmatic cycle both elements are enriched in course of the differentiation and are mainly integrated into minerals of the late crystallisation phase. The average abundance of thorium in the earth's crust is about $12 \mathrm{ppm}$, whereas the abundance of uranium is only about 3 ppm. Thorium and uranium show a high adsorption power to clay minerals, oxides and hydroxides. Therefore, high contents of thorium can be found, for example, in bauxite and bentonite (Siehl, 1996). In sedimentary rocks, quartz rich sandstones and limestones contain low concentrations of uranium, whereas due to the adsorption of uranium in clay minerals, clayey sediments exhibit rather high values (Siehl, 1996).

The only man-made nuclide, which is present in significant amounts in most soils on the Northern Hemisphere, is ${ }^{137}$ Cs. During the last decades it has been accumulated on the ground due to atmospheric fall-out from nuclear weapon tests and nuclear power plant accidents like those from Chernobyl and Fukushima. Due to its long half-life of $30.17 \mathrm{yr}$, it is still relatively abundant in European soils.

\subsubsection{The measurement principle}

The gamma-ray spectrometer consists of several sodiumiodide crystals, which convert gamma radiation into flashes of light. These are detected by a photo-cathode and converted into an output voltage, which is proportional to the energy of the incident gamma-ray. With conventional measuring systems, the energy spectrum between 0.2 to $6.0 \mathrm{MeV}$ is resolved in 256 channels. Since the air layer between helicopter and ground absorbs gamma radiation (depending on the physical condition of the air), the exact flight altitude, air pressure, air temperature as well as air moisture have to be taken into consideration when correcting survey data. The recorded data has to be corrected for background radiation, Compton scattering and variation of sensor altitude (for details of gamma-ray processing see Minty et al., 1997) and vegetation thickness (Ahl and Bieber, 2010). 


\subsubsection{Investigation depth}

When gamma rays pass through matter, they lose part of their energy through scattering and absorption. Since a gamma ray photon loses about half of its energy with each scattering event, most gamma rays detected at airborne survey heights originate from the first $30 \mathrm{~cm}$ of the subsurface.

\subsection{Passive microwave measurements}

The superficial soil moisture can be determined by passive microwave surveys, since the emission of thermal microwave radiation is strongly dependent on the soil moisture content (different dielectric constant). The content of soil water is of great importance for many hydrological, agro-meteorological, ecological, as well as biological processes since the water content close to the surface controls the energy exchange between soil and atmosphere. The link between soil moisture, evaporation and transpiration is of utmost importance for predicting reciprocal influence of ground surface on climate and weather. Conventionally, such survey systems are mainly used for determining water movements near ground surface and estimating the spread of precipitation over large areas.

\subsubsection{The measurement principle}

For estimating soil moisture (in water content percentage) within the first centimetres of the subsurface, a passive microwave antenna is used, which is attached to the bottom of a helicopter. The antenna measures the microwave radiation from the ground, reflected in the L-Band (1400 to $1427 \mathrm{MHz}$ for the sensor in use at Gschliefgraben). The intensity of this radiation correlates with the water content in the soil and is influenced by the surface temperature, surface roughness as well as vegetation. The "penetration" depth of this method is $5-10 \mathrm{~cm}$.

\section{The study area}

The Gschliefgraben site (Fig. 1) comprises one of the most prominent and extensively studied slope failures of recent time in Central Europe (Supper et al., 2010). Gschliefgraben is a $2.85 \mathrm{~km}$ long and $0.85 \mathrm{~km}$ wide valley along the front of the Northern Calcareous Alps (Fig. 3) at the foot of Mt. Traunstein (1691 ma.s.l.), south of the town of Gmunden. The valley is divided into small sub-parallel catchments; its topography is strongly controlled by complicated tectonics and a very complex lithology, as well as by mass wasting that has been active here since the end of the last glacial period.

The Gschliefgraben includes a large complex of geologically controlled landslides, earth flows, topples, rockfalls and deep-seated gravitational deformations. In late November 2007, an earth flow of about 3.8 million $\mathrm{m}^{3}$ of colluvial mass was reactivated in the central and western parts of the valley. The displacement velocity was up to $4.7 \mathrm{~m} \mathrm{day}^{-1}$ in the beginning. Consequently, in frame of the first emergency measures, 55 buildings had to be evacuated (Marschallinger et al., 2009).

\subsection{The geological setting of the investigated area}

The surveyed area comprises four main geological units $(\mathrm{Eg}$ ger, 1996; Egger and van Husen, 2007; Rupp et al., 2011; Prey, 1983) with a different lithology (Fig. 3) i.e. (from South to North): (i) Northern Calcareous Alps and the "Marginal nappe" (NCA), (ii) Ultrahelveticum (UHV), (iii) the Rhenodanubian flysch zone (RFZ) and Quartenary deposits (QD). For the following sections the defined abbreviations for these four main units will be used.

The NCA unit (Triassic-Cretaceous age) is mainly composed of densely fractured, diversely stratified, steeply dipping and frequently faulted competent brittle carbonate rock. "Hauptdolomit" and Wetterstein limestone are the most abundant rock types. The substrate is highly permeable and the joints often have a character of opened cracks.

The central part of the Gschliefgraben valley is built up by the Buntmergelserie (index 50 in Fig. 3) as part of the Ultrahelveticum (UHV) nappe (Cretaceous-Paleogene age), which emerges here in form of a tectonic window between the RFZ and the NCA (Rupp et al., 2011). It mainly comprises tectonically strongly deformed, variegated marl, claystone, nummulitic limestone, sandstone, arkose, etc. This unit is the most incompetent one within the study area. The material contains a relatively high fraction of swelling clay minerals. Moreover the soft rocks are intensively tectonically fragmented. Within the Buntmergelserie impermeable zones prevail. Another part of the UHV nappe, the Gresten formation (index 52 in Fig. 3), composed of sandstones and situated stratigraphically below the Buntmergelserie, crops out at several locations around the Laudachsee.

The RFZ (Cretaceous age), part of the Penninicum nappe and the Flysch main nappe, is mainly composed of claystone, cemented marl and sandstone of different thickness. In the investigated area (from bottom to the top) the Reiselberg formation (clay and marl stone, index 60 in Fig. 3), the Seisenburg formation (mainly claystones with occasional sandstone beds, index 59 in Fig. 3), the Kalkgraben/Zementmergel formation (marl lime, calcareous sandstone, index 58 in Fig. 3) and the Altlengbach formation (sandstone, index 57 in Fig. 3) occur. The youngest rocks comprise the QD.

During the last glacial period, part of the investigated area was significantly reshaped by two glaciers (van Husen, 1987). One originated below the Traunstein summit, leading through the Gschliefgraben, at which base it merged with the main Traunsee glacier. The other one initiated at the Hohe Scharte, passed northwards over the area of the Laudachsee and proceeded into the Laudach valley (van Husen, 1987). A 


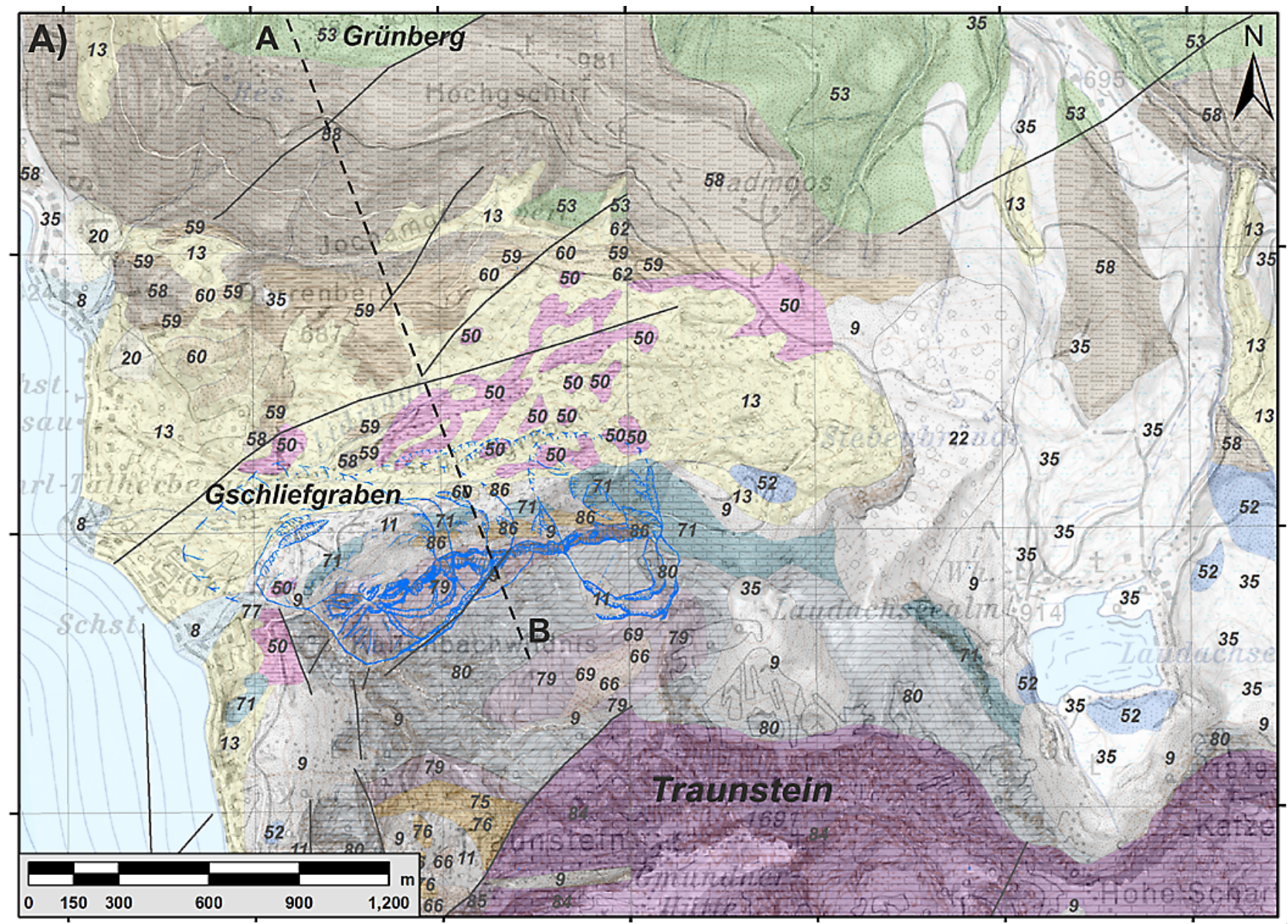

B)

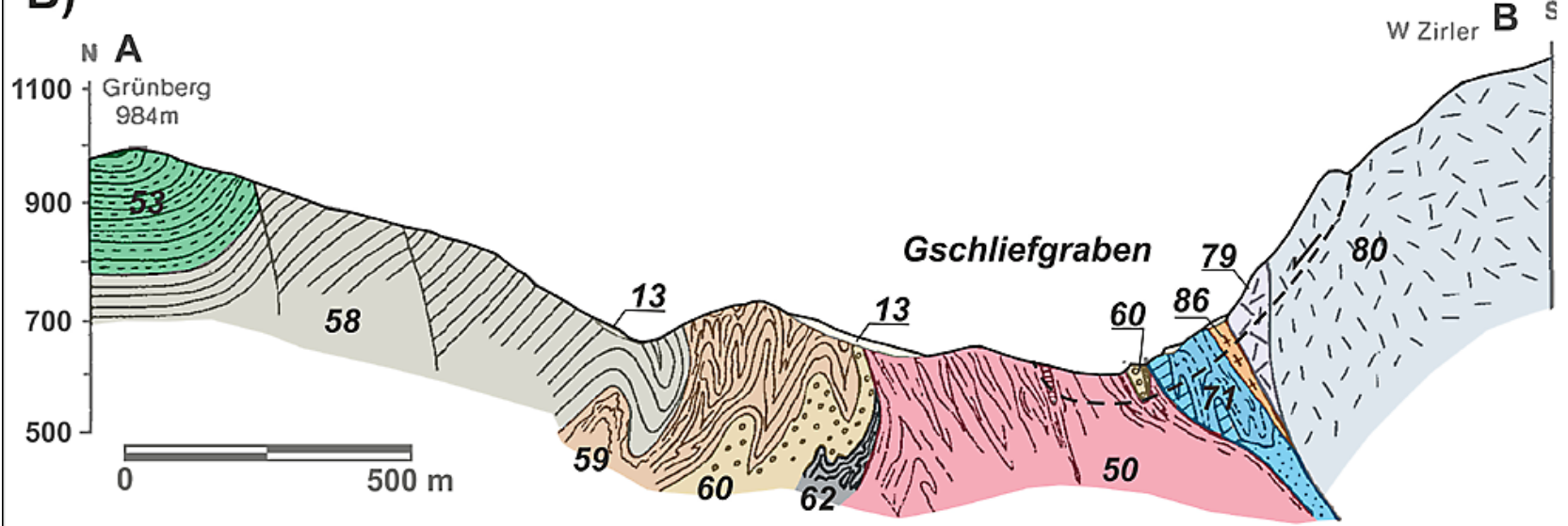

Fig. 3. Geological map of the area of Gschliefgraben. The blue contours indicate the deep-seated gravitational deformations. Legend: Quaternary deposits: 8 - alluvial fan, 9 - slope scree, 11 - block fields, 13 - landslide deposits, 20 - Glaciolacustrine deposits, 22 - slope breccia, 35 - moraine deposit; UHV: 50 - Buntmergelserie, 52 - Gresten Fm.; RFZ: 53 - Altlengbach Fm., 58 - Zementmergel Fm., 59 - Seiesenburg Fm., 60 - Rieselsberg Fm., 62 - Gaultflysch Fm.; NCA: 66 - Schrambach Fm., 69 - Ruhpolding Fm., 71 - Calcarenite Fm., 75 - Koessen Fm., 76 - Koessen Fm., 77 - Koessen Fm., 79 - Plattenkalk Fm., 80 - Hauptdolomit Fm., 84 - Wetterstein Fm., 85 - Guttenstein Fm., 86 - Haselgebirge Fm.; the major tectonic faults are represented by solid lines (modified after Schoenlaub et al., 1996; Krenmayr, 2007 and Moser, 2009). 
ridge, composed of Quaternary slope-scree breccia (index 22 in Fig. 3), was left between the two former glaciers.

In the surroundings of the Laudachsee, the bedrock units are mostly covered by glacial moraine deposits (index 35 in Fig. 3) and mass movement deposits (index 13 in Fig. 3).

The main recent mass wasting processes are represented by slides and flows in the central part of the Gschliefgraben valley, which is built up mostly of the Buntmergelserie (see Fig. 4). On the other hand, falls, topples, and spreads are the most characteristic types of mass movement in the eastern and southern marginal areas of the valley along NCA, where hard rock dominates (dolomite, limestone and cemented Pleistocene breccia). At some places, great portions of the NCA and the below situated RFZ and UHV units are most likely subject to deep-seated gravitational deformations in a rather initial evolution stage.

\section{Results of the airborne mapping campaign at the Gschliefgraben test site}

In the aftermaths of the Gschliefgraben event of 2007, a multi-parameter airborne geophysical survey was conducted as part of a complex investigation strategy to explore the detailed structure of the landslide. The helicopter borne geophysical campaign was performed in September 2009. Due to the rough topography, the survey area was separated into two parts, one part covering the area of the recent activity and the other one the probable catchment area in the east, with different line orientations (Fig. 5), to ensure a sensor altitude of less than $90 \mathrm{~m}$. Due to the steep inclination of the survey area, lines could only be flown in an uphill direction. Thus, twice as much flight time had to be used than for usual survey flights.

After applying the usual processing steps (e.g. noise filtering, drift correction, laser altitude correction), the data (or the derived model outputs in case of electromagnetics) were analyzed and compared to the landslide inventory map and the geological map. The interpretation was supported by geological maps, compiled by Egger (1996), Egger and van Husen (2007) and Moser (2009), structural palaeostress analysis and by a high-resolution ground geoelectrical survey (13 profiles).

\subsection{Results of electromagnetic mapping: subsurface resistivity}

The electromagnetic data were inverted to determine the subsurface resistivity distribution by applying a one-dimensional multi-layer inversion code (EM1DFM, 2000). Grids of the subsurface resistivity at several depths parallel to the surface, as well as depth slices along selected profiles, were derived.

Figures 6 and 7 show the resistivity distribution in the depth range $0-2 \mathrm{~m}$ and $20-22 \mathrm{~m}$ below surface. These maps are selected as examples to discuss some general pattern of the resistivity map in correlation with the general geology (Fig. 3) and the landslide inventory (Fig. 4).

\subsubsection{Results in the Gschliefgraben area}

In general, the marls of the Buntmergelserie exhibit the lowest values of resistivity. The border of the $2-30 \mathrm{Ohmm}$ (blue coloured) resistivity-range well delineates the lateral as well as depth borders of this unit. A comparison with the landslide inventory map proves that almost all recent landslides and earth flows can be contributed to the Buntmergelserie. The low resistivity values further confirm that this unit is the most incompetent one within the survey. Some of the resistivity-depth slices suggest that this unit dips towards the north under the RFZ (Fig. 8, profiles 1, 4, 5, 6,7) and towards south beneath the NCA (Fig. 8, profiles 3, 4, 5). The locations of the resistivity-depth slices are shown in Fig. 9. The structures derived from the resistivity depth slices also verify that the Buntmergelserie emerges as a highly tectonised, anti-synclinal fold, with a strongly west-east dipping axis. This fact further supports the development of instabilities. As the lateral spread of the low resistivity area shows, the Buntmergelserie extends from the Traunsee up to the Laudachsee area, where it is covered by a layer of glacial sediments (high resistivity; Fig. 8, profiles 7, profile distance 3200 to 4500 ). In the area of Siebenbründl (Fig. 8, profile 7, profile distance between 2300 and $3000 \mathrm{~m}$ ), a thick layer (up to $40 \mathrm{~m}$ ) of high resistive ( $>300 \mathrm{Ohmm}$ ) slope breccia, situated in the gap between the two former glaciers, was found. The electromagnetic depth slice, as well as a geoelectric multi-electrode section (Fig. 10, profile G1, profile distance 330 to $820 \mathrm{~m}$ ) verify the thickness of the sediment (mostly moraine) cover at this location and the continuation of the Buntmergelserie below. The areal pattern of near-surface resistivities (Fig. 6) however shows very low resistivity values only in the central part of the Buntmergelserie. Those regions correlate well with areas characterized by active movements.

\subsubsection{Results in the area north of Gschliefgraben}

Towards the north and east, the low resistivity region, marking the outcrop of the Buntmergelserie, is framed by areas of medium (50-100 Ohmm) and high ( $>150 \mathrm{Ohmm}$ ) resistivity, which can be associated with different lithological units of the RFZ. Medium resistivities correlate with claystone and marl, whereas a high resistivity refers to intermediate sandstone layers. Resistivity depth slices (Fig. 8) show that the RFZ ridge south of the Jochamgraben shows a change in its structure from east to west. In the east it is composed only of a thin marl layer (medium resistivity, Reiselberg formation) on top of the Buntmergelserie (Fig. 8, profiles 4, 5). Towards north in the Jochamgraben (e.g. middle part of profiles 4 and 5), low resistivities close to surface indicate that the Buntmergelserie almost outcrops again. North of the Jochamgraben, the medium resistivity marl layer is followed 


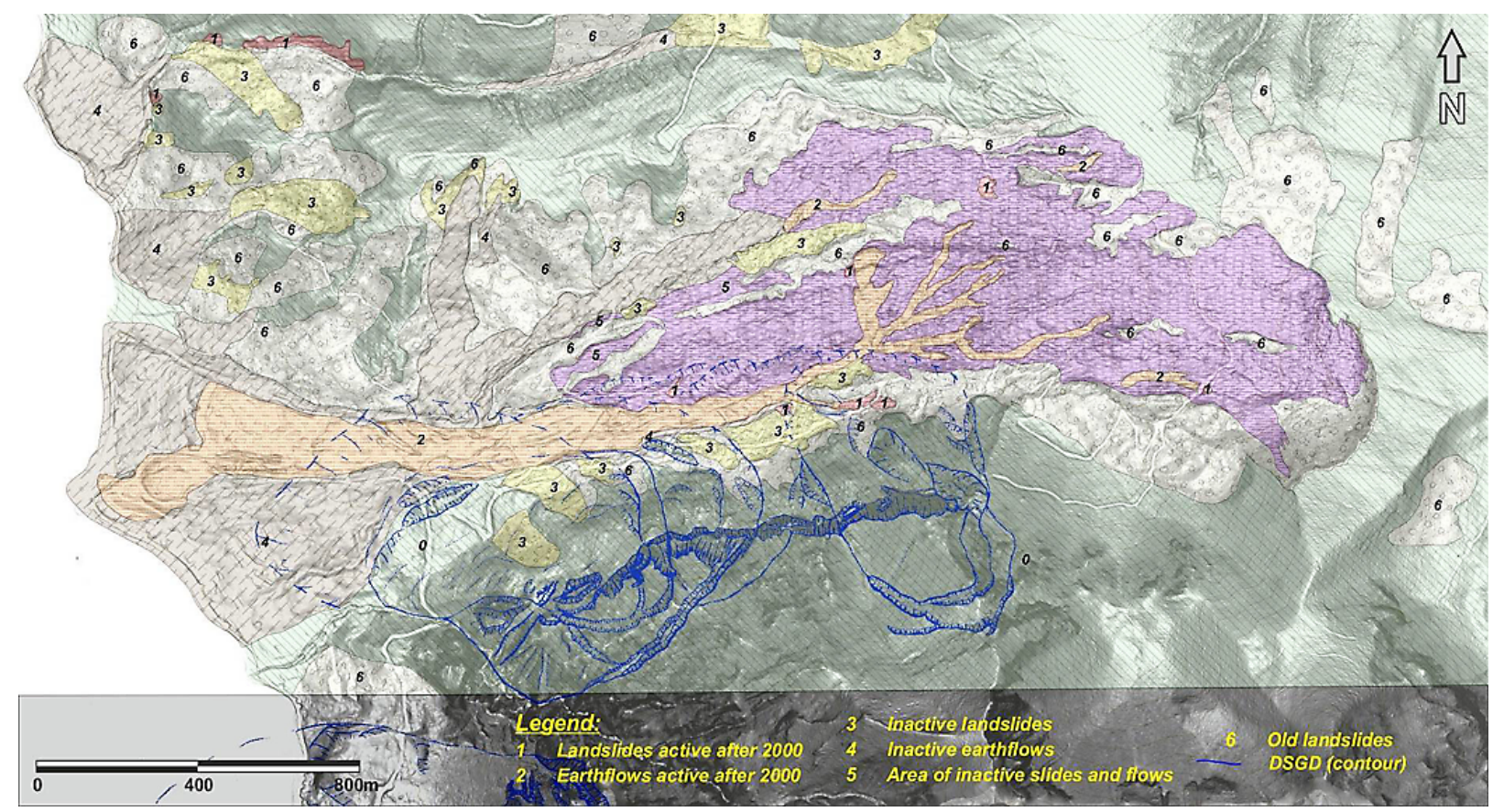

Fig. 4. Landslide inventory map of the area of Gschliefgraben. Slope failures comprise more than $50 \%$ of the area.

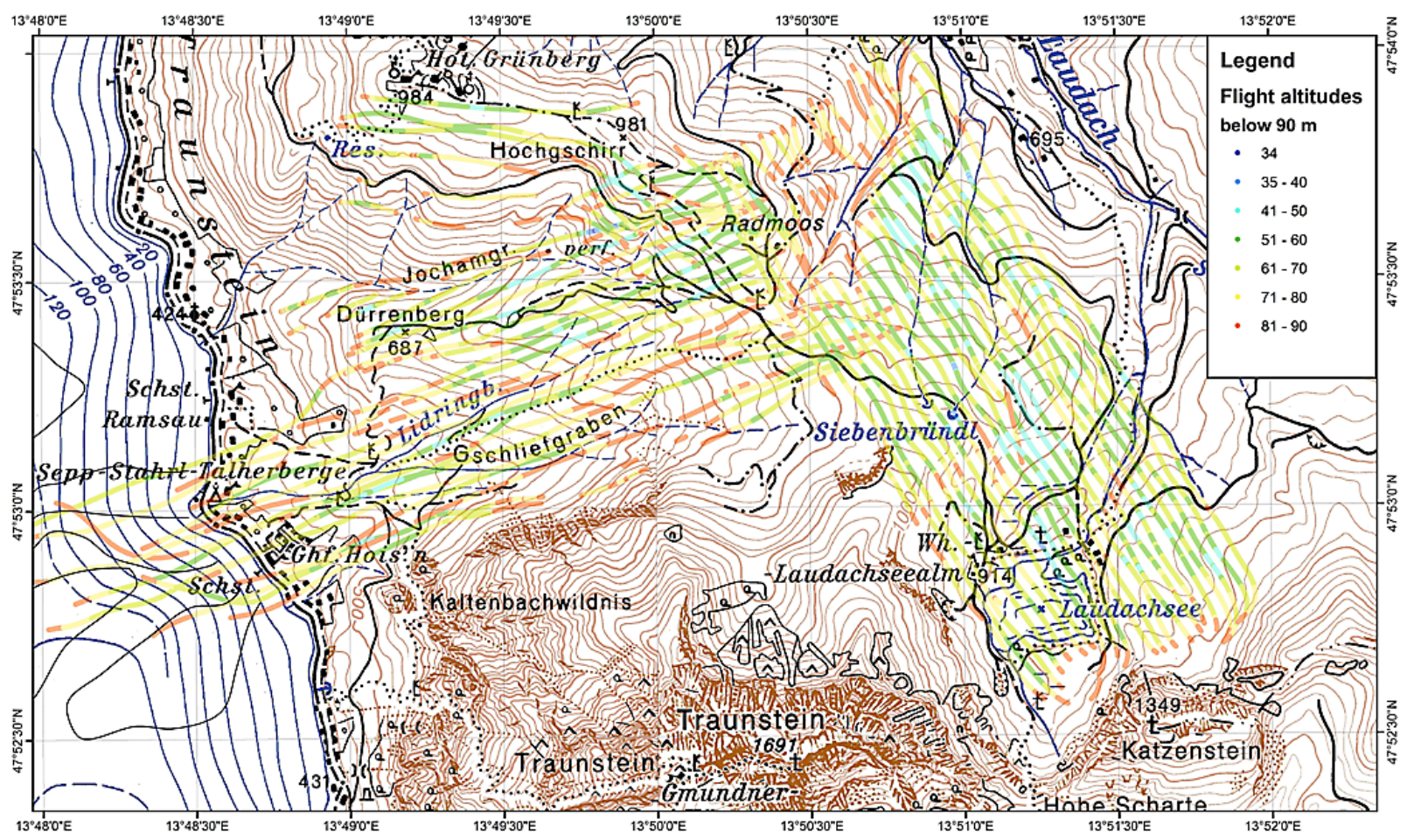

Fig. 5. Flight lines of the Gschliefgraben airborne survey; colours indicate the actual sensor height (m) above topography.

by a thick high-resistive sandstone layer (most probably a part of the Kalkgraben formation), topped by a medium resistive marl/claystone stratum (Altlengbach formation).
Further to the west, the thickness of the RFZ layers increases significantly. The high-resistivity values indicate the existence of sandstone strata also south of the Jochamgraben. Here, the penetration depth of the method was not large 


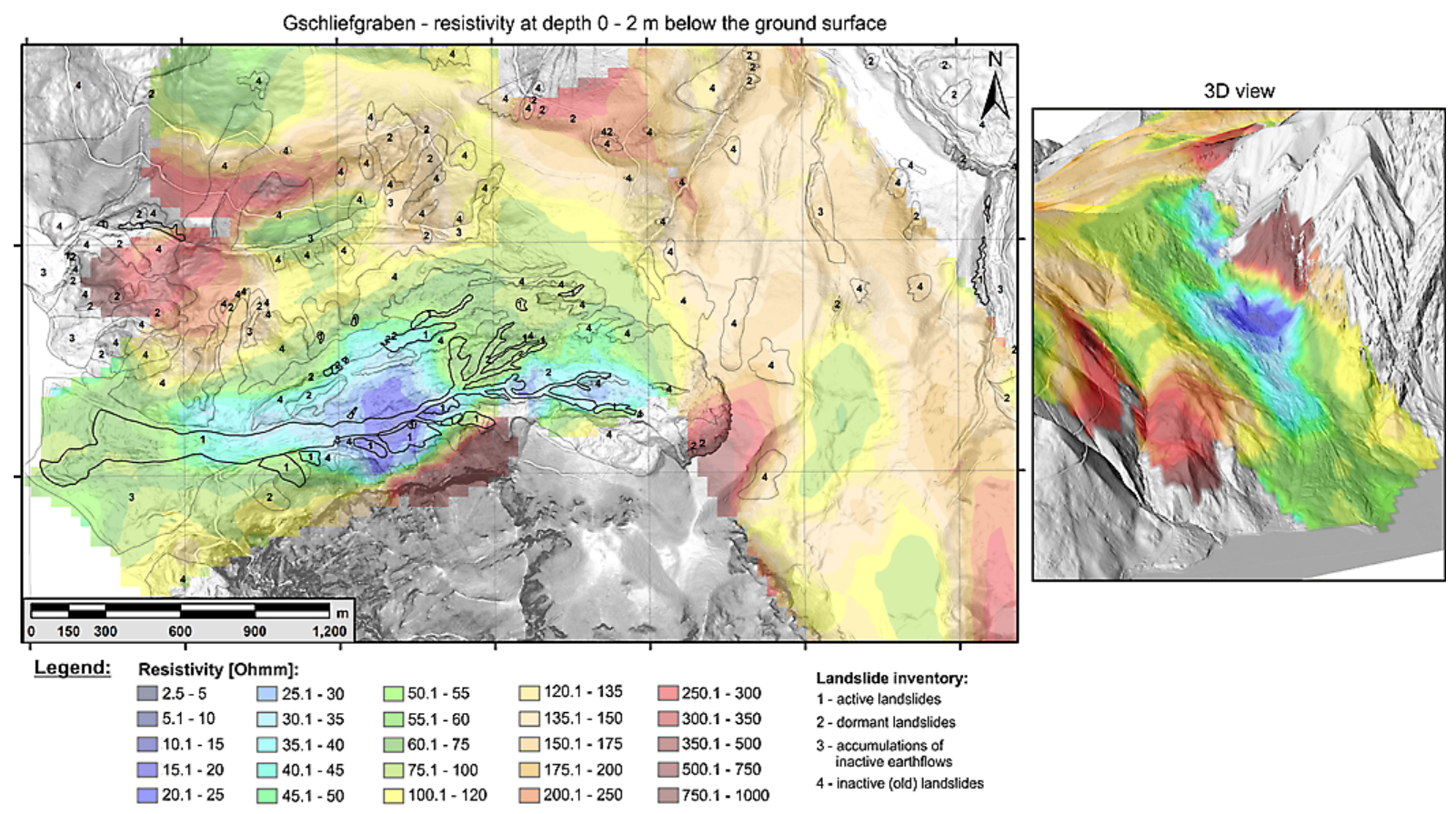

Fig. 6. Map of the subsurface resistivity derived from AEM data (depth slice) at depth 0-2 m below the ground surface compared to the landslide inventory map; right side: 3 -D view from the west.

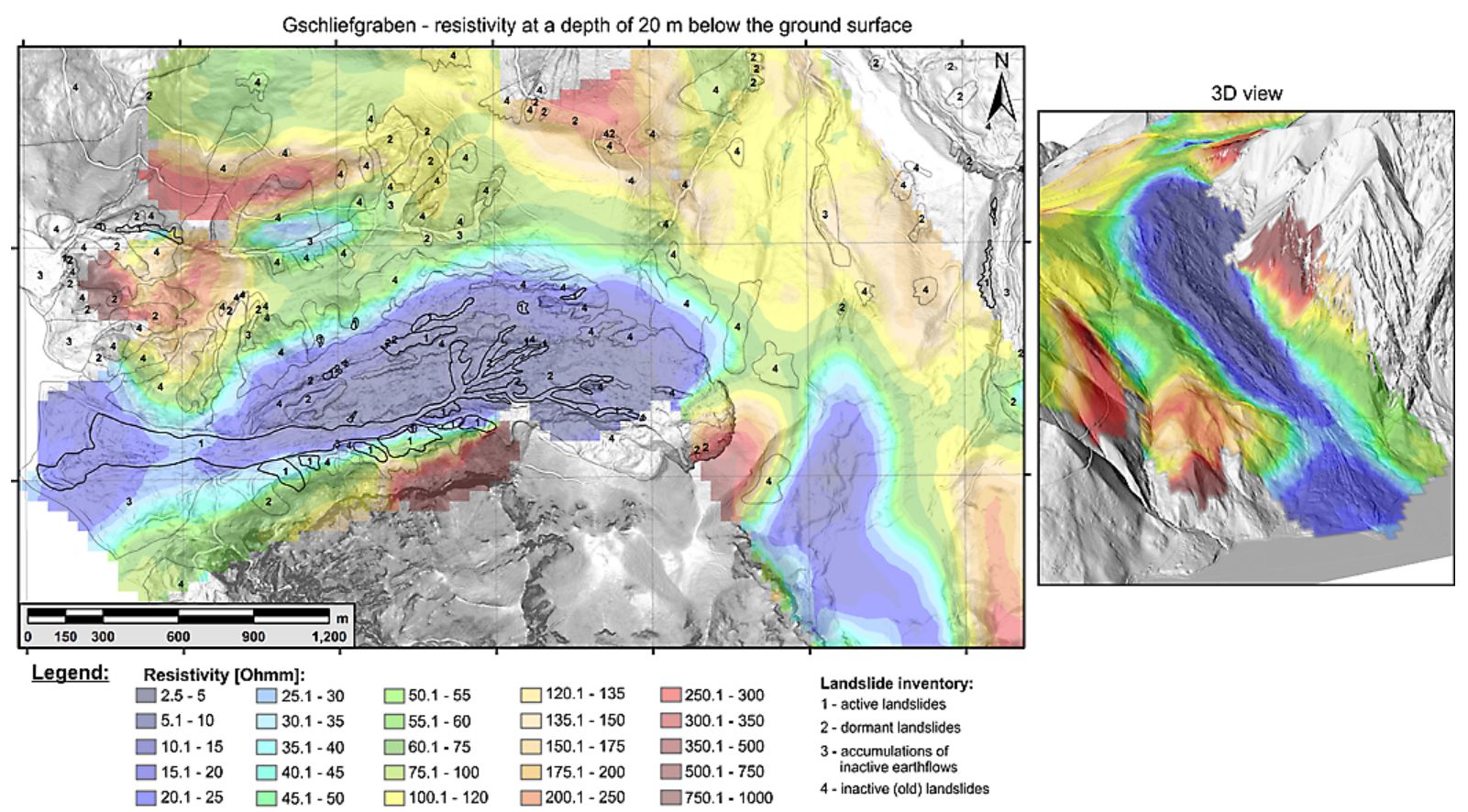

Fig. 7. Map of the subsurface resistivity derived from AEM data (depth slice) at a depth of $20 \mathrm{~m}$ below the ground surface compared to the landslide inventory map; right side: 3-D view from the west.

enough to track the dipping of the Buntmergelserie beneath the RFZ. North of this area, no data is available.

\subsubsection{Results in the area south of Gschliefgraben}

The high resistivities south of the Buntmergelserie (Fig. 8, profiles $3,4,5$ ) can be contributed to limestone and 

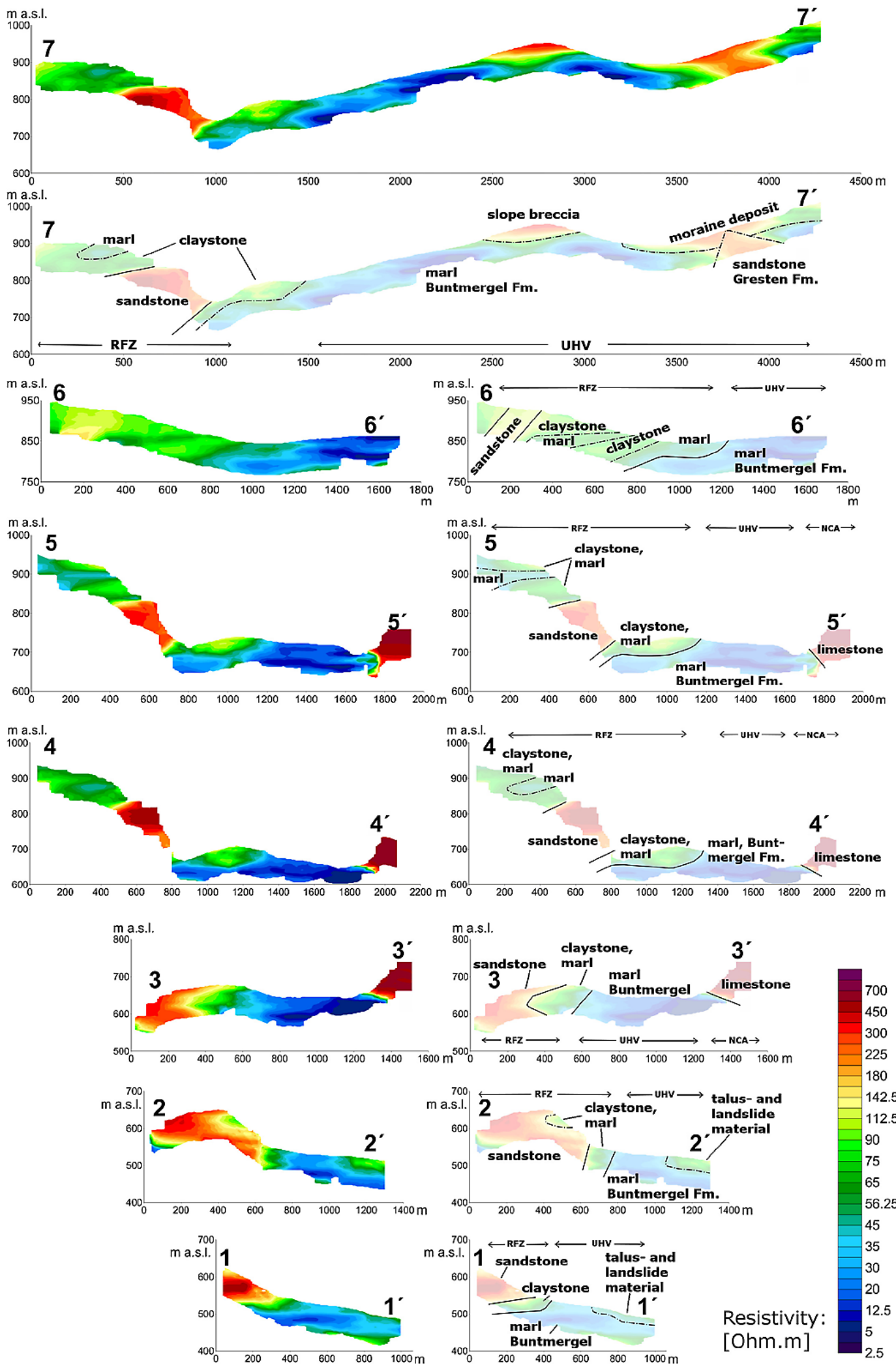

Resistivity: [Ohm.m]

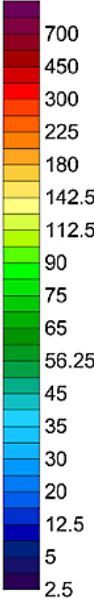

Fig. 8. HEM cross sections obtained from the 1-D multilayer inversions; their positions are marked in Fig. 9 (black lines); HEM cross sections with lower colour contrast include geological information for a detailed interpretation of the derived resistivity pattern. 

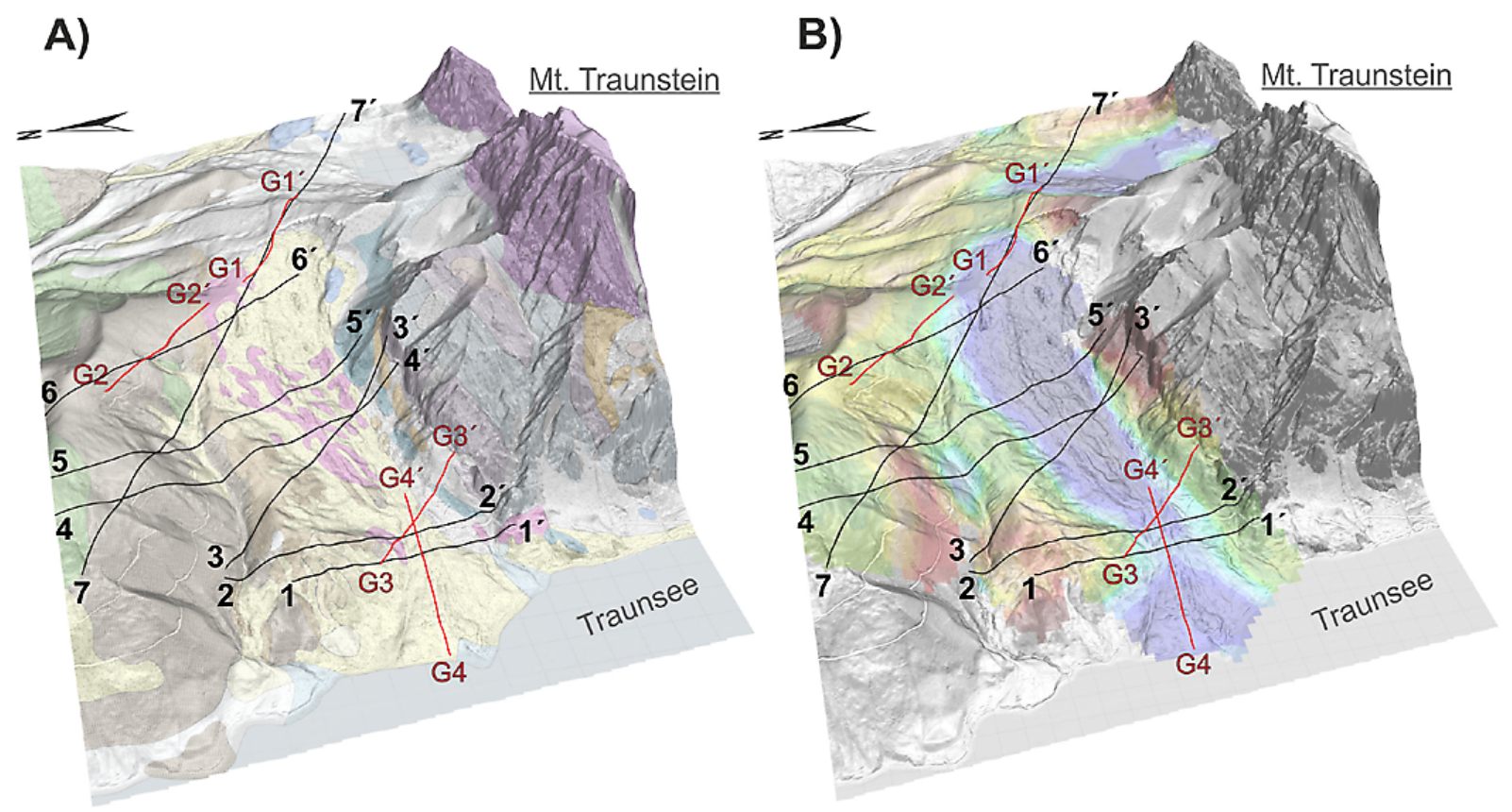

Fig. 9. 3-D view of the geological (A) and electromagnetic (B) map seen from the west; black lines: locations of the HEM cross sections; red lines: locations of the geoelectric profiles.

dolomite rocks, slope scree (and cemented slope breccia), crushed zones and opened cracks in NCA. The southern high-resistivity areas correlate well with the mapped deepseated gravitational deformations of the northern slopes of Mt. Traunstein.

A total of 13 multi-electrode profiles were measured to verify the reliability of the inversion results. Figure 8 shows the location of selected lines, whereas Fig. 10 displays the results of the resistivity inversion of selected geoelectrical profiles using a similar colour bar like the one used for the electromagnetic cross sections.

All results verify the general resistivity pattern derived from the airborne survey. However, the results also show that using ground geoelectrics, the internal structure of the landslide body itself could be resolved with a much higher detail. The resolution of the airborne electromagnetic mapping was not enough to determine the internal structure of the low resistive landslide body due to its very limited resistivity contrast $(5-50 \mathrm{Ohmm})$ and the small size of its internal stratification.

\subsection{Results of gamma ray mapping}

\subsubsection{The distribution of thorium and potassium}

The results of the gamma-ray survey clearly show that the content of the radioactive elements potassium and thorium (Figs. 11 and 12) is expressively related to the lithology of the parent material. The distributions of both elements exhibit very similar pattern. In general, high concentrations of potassium and thorium are found in areas composed of clay, marl and clay stone of the UHV and RFZ, whereas the absolute value depends on the degree of weathering (i.e. strongly weathered marls or clays show higher rates than marl and clay stone areas). Therefore, the highest potassium and thorium contents were mapped in colluvial deposits of inactive dormant or old landslides in the RFZ, as well as in deposits of the active and dormant landslides/earthflows of the UHV.

Low contents are mostly correlated with material of the NCA in the south and southeast of the investigation area and with some of the sandstones outcrops of the RFZ. Therefore rocks and slope scree of the entire NCA, cemented breccias (index 22 in Fig. 3) in the SE of the survey area, as well as large alluvial fans and the lowermost portion of the Gschliefgraben earthflow, exhibit low concentrations. The lowest values were detected along loosened and crushed limestone, opened cracks as well as along zones of detachment of the DSGD.

A direct relation between the content of radioactive elements and individual landslide bodies is difficult to establish due to the relatively low spatial resolution of the survey and very complex mass wasting processes at the Gschliefgraben site. However, some interesting conclusions can be derived on the dynamic evolution of the landslides inside the Gschliefgraben valley: focusing on the area mostly involved by the recent events, a clear separation into areas with different characteristics of radioactivity can be recognised. Just west of the main scarp of the landslide complex, quite low values show that, probably due to mass wasting processes, 


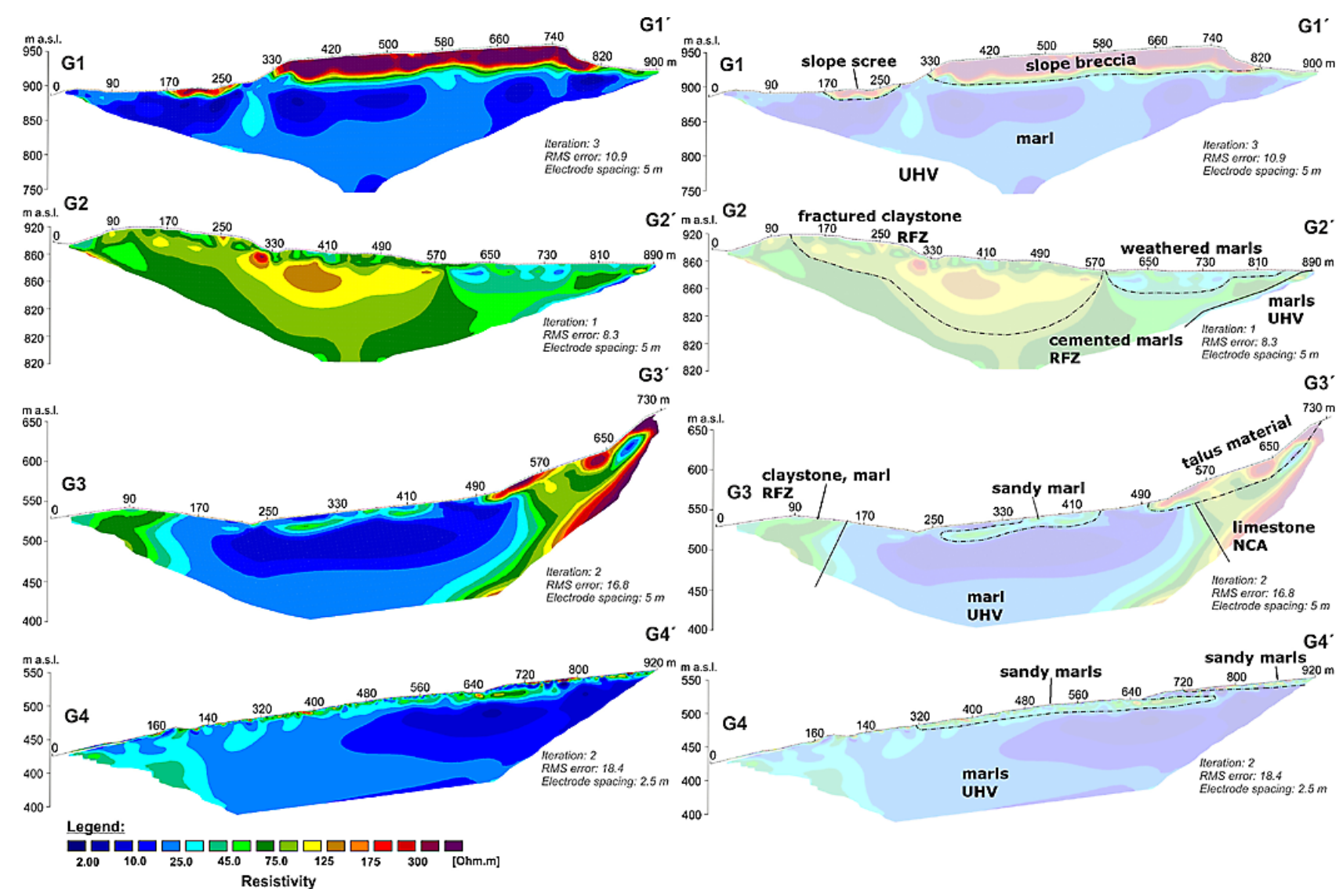

Fig. 10. Inversion results of geoelectrical multi-electrode profiles (left), results with low colour contrast including geological information (right); for location see Fig. 9 (red lines, profiles G1-G4).

the underlying clays of the UHV are covered by mobilized material from the Quaternary sediment ridge (index 22 in Fig. 3) and/or limestone and dolomite scree from Mt. Traunstein. Further to the west, the results show high contents of potassium as well as thorium, indicating that the surface material is dominated by highly weathered clay and marl components of the UHV unit. In the middle part of the recent sliding area, an alteration of high and low values (mostly expressed in the thorium pattern) can be determined from east to west. This pattern is most probable due to different, alternating inflow of material from the UHV unit (high values) and rockfall material (limestones, low values) from the NCA.

In the most western part, the area influenced by recent sliding is sharply delineated to adjacent historical landslide material in the north by a sharp contrast from low to high values. Field inspection proved the occurrence of coarser sediments with higher limestone content, thus causing lower count rates. However, in this region the top layer of the original landslide material was removed during the phase of remediation. An isolated anomaly with higher values in the southwestern area can be correlated with historic landslide bodies.

\subsubsection{The distribution of uranium}

The distribution of uranium does not display a distinct pattern and seems rather randomly distributed. This is most probably due to the fact that uranium sources are missing in the investigation area. Therefore a further interpretation cannot be provided.

\subsubsection{The distribution of ${ }^{137} \mathrm{Cs}$}

The map of the ${ }^{137} \mathrm{Cs}$ distribution (Fig. 13) offers an interesting tool to determine areas, which had been involved in mass wasting processes. Since ${ }^{137} \mathrm{Cs}$ is usually deposited only in the first decimetres of the soil, areas with very low ${ }^{137} \mathrm{Cs}$ activity correlate well with regions, where the top soil was removed due to sliding processes (or to engineering measures). In Fig. 13, areas, which were involved in the recent sliding events, are clearly marked by a low ${ }^{137} \mathrm{Cs}$ content (blue colours) in the shallow subsurface layer. Therefore the extent of recent events can easily be mapped with this method. 


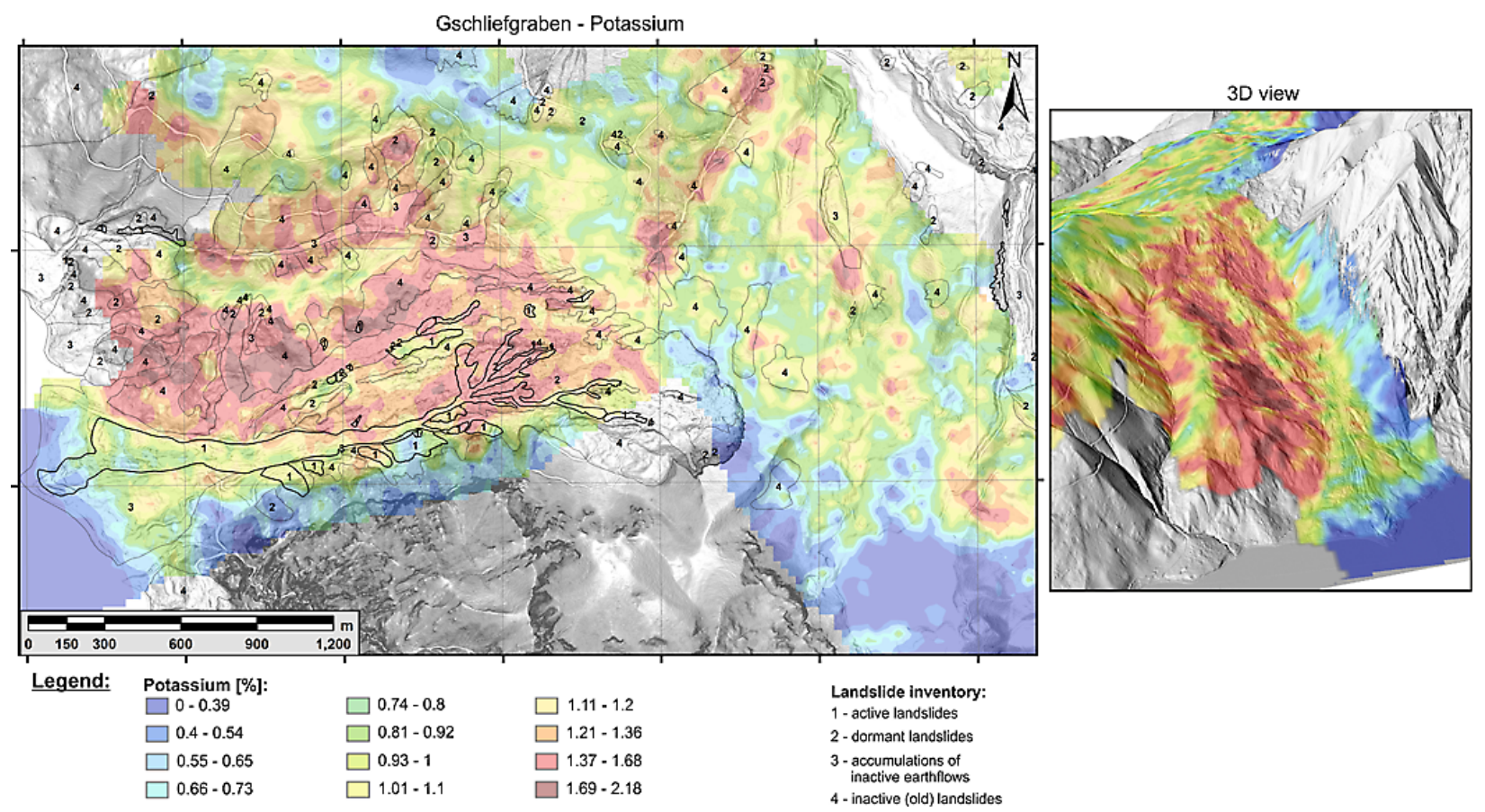

Fig. 11. Map of the potassium content at the ground surface compared to the landslide inventory map; right side: 3-D view from the west.

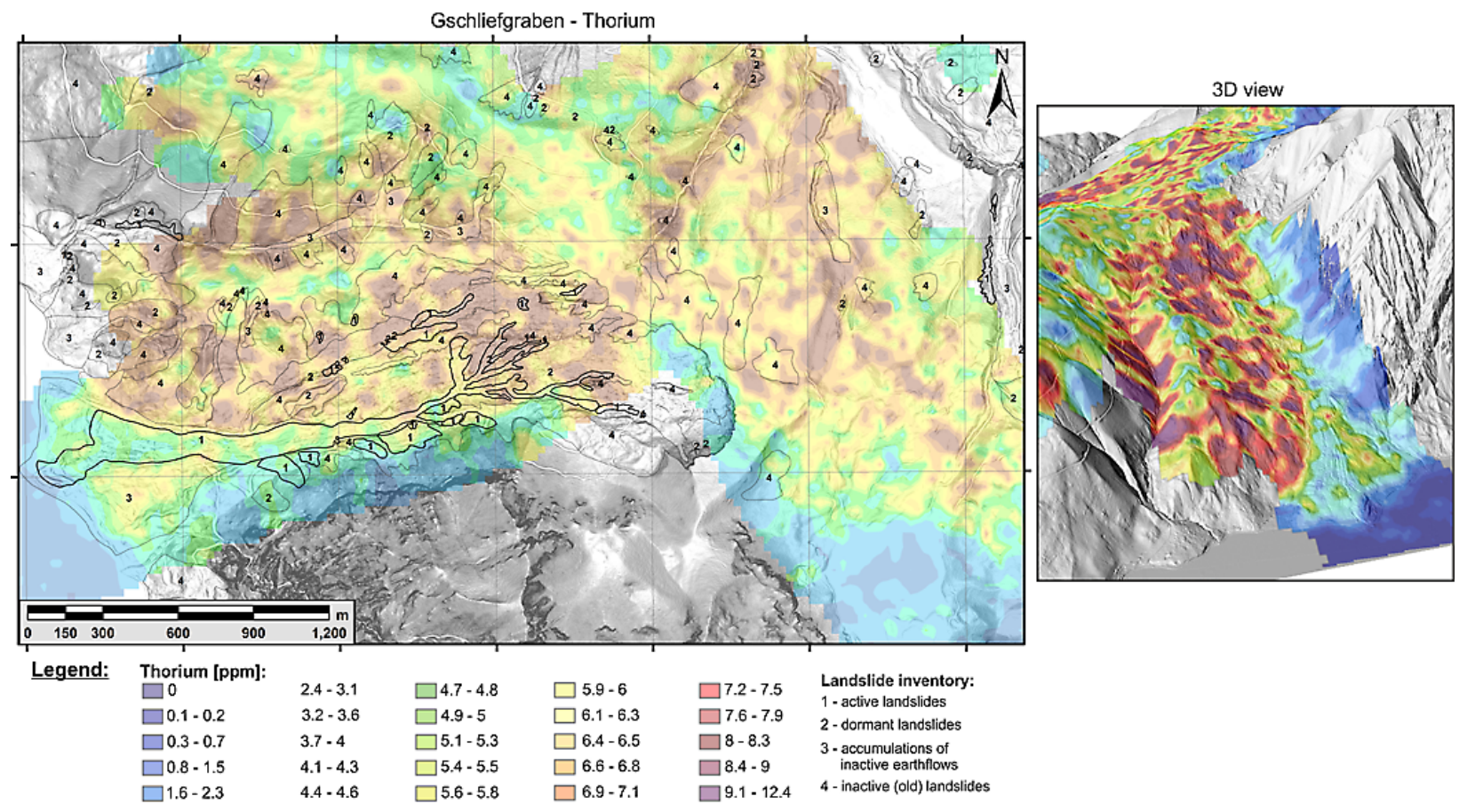

Fig. 12. Map of the thorium content at the ground surface compared to the landslide inventory map; right side: 3-D view from the west.

\subsection{Soil humidity mapping}

The results of the passive microwave survey (Fig. 14) provide information on the superficial soil moisture. The highest soil water content was mapped within the zone of the recent earthflow, along the foot of the NCA in the central part of the valley, especially in regions, where still significant movements are going on. It could indicate intensive infiltration of karst water from the NCA. Since active landslides are often correlated with high surface water content, soil moisture 


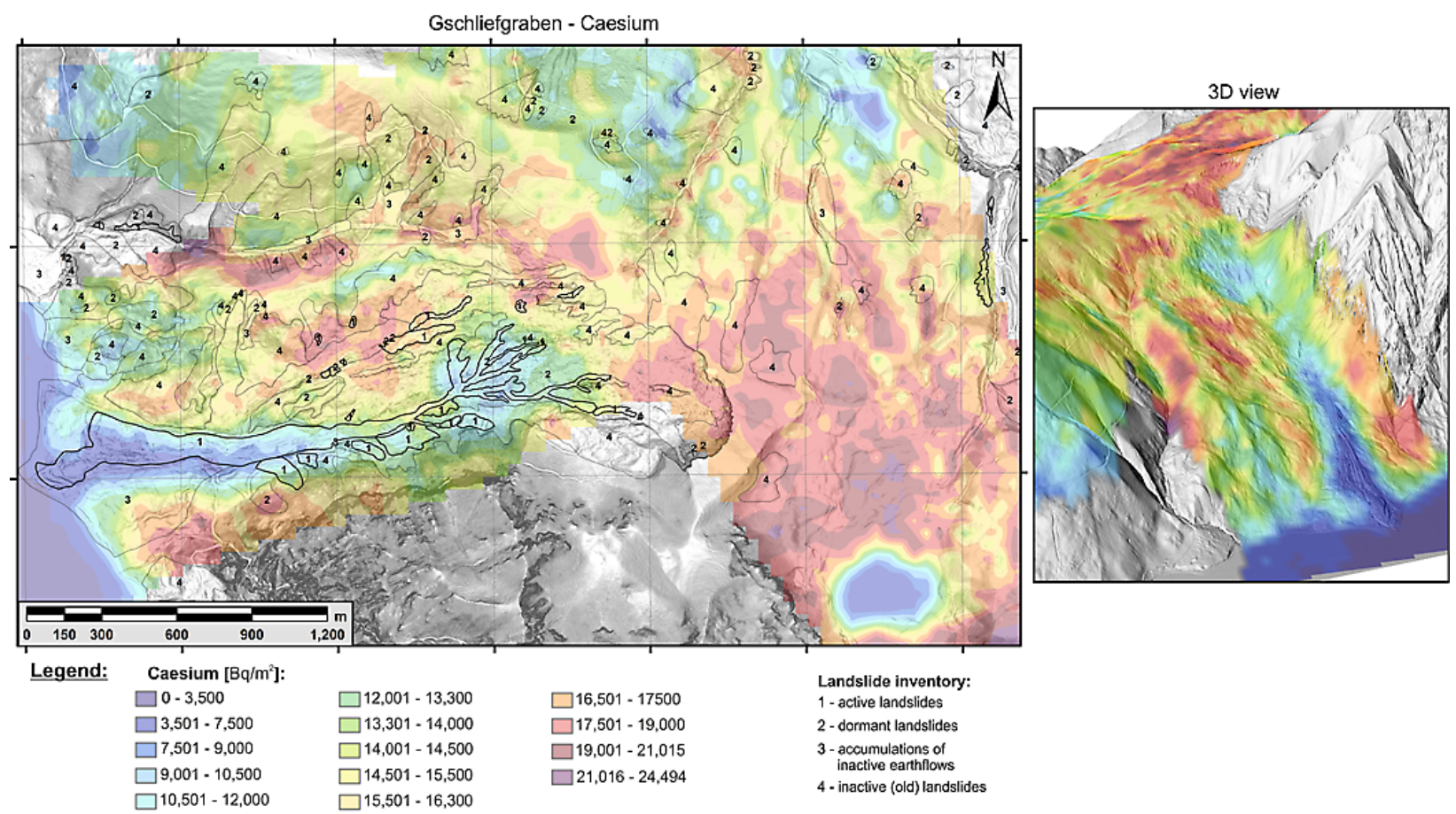

Fig. 13. Map of the Cs activity compared to the landslide inventory map; right side: 3-D view from the west.

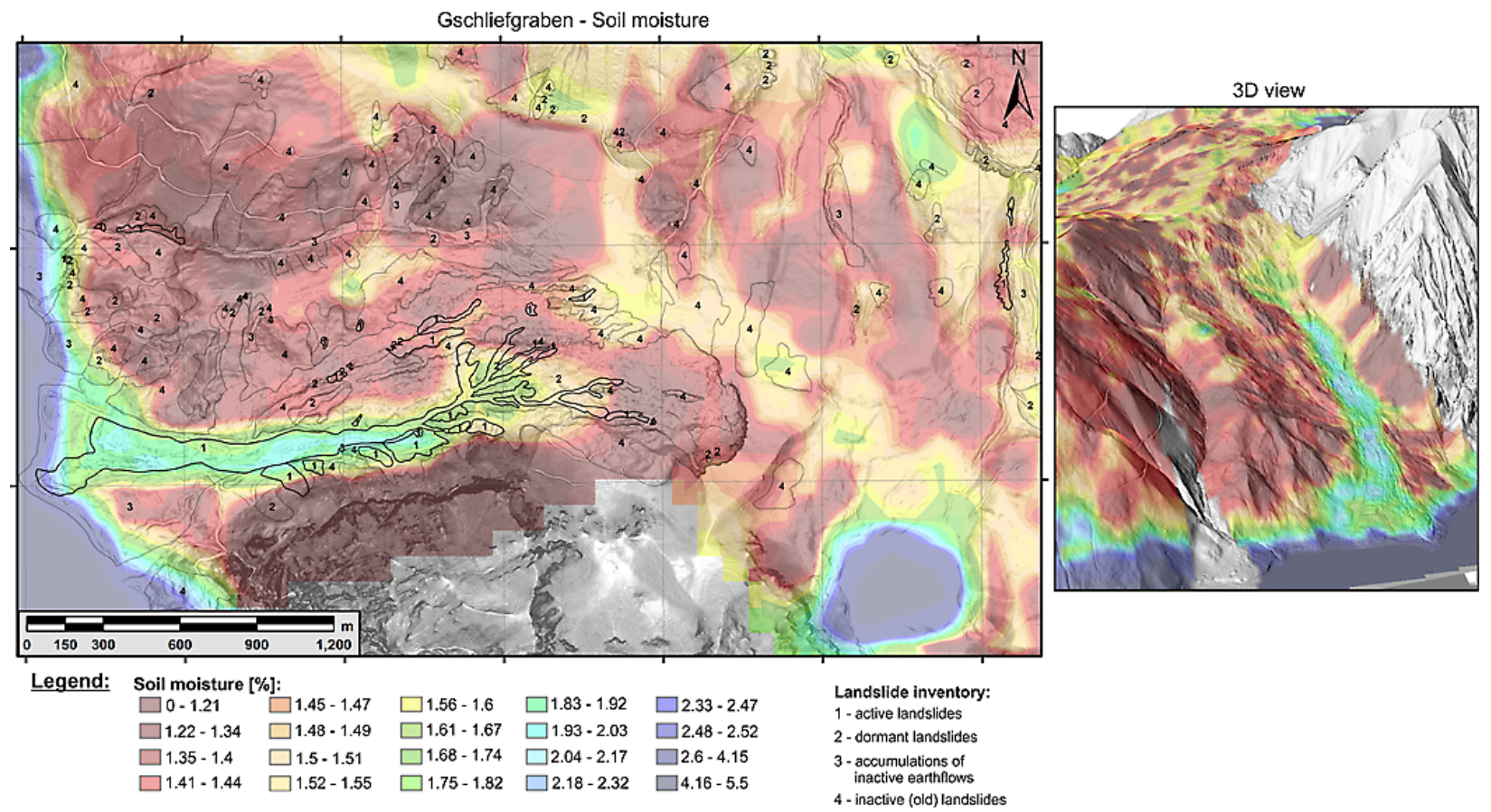

Fig. 14. Map of the soil moisture near the ground surface, which was obtained from the passive-microwave survey, compared to the landslideinventory map.

surveying seems to be a promising indicator of active mass movements.

\section{Interpretation of results from the Gschliefgraben area}

The results of the electromagnetic mapping campaign show that within the test site, low resistivity values well delineate 
areas with a high potential for future landslides. The results suggest that not only the Gschliefgraben valley, where the recent sliding event took place, but also the Lidringbach valley exhibits a high potential for future mass wasting processes. From the geophysical signature, both valleys can be characterized as very similar. Only the parameter surface soil humidity shows higher values in those areas inside the Gschliefgraben valley, which still exhibit significant rates of displacement.

Since the Buntmergelserie continues to the east below the slope scree breccias (index 22 in Fig. 3), infiltration of significant amounts of water to the Gschliefgraben valley from the Laudachsee catchment area is very unlikely. However, the penetration depth of the survey was not enough to investigate if the sandstone layers (index 52 in Fig. 3), that outcrop in the Laudachsee area and which are supposed to belong to the Gresten formation (a unit that should be located beneath the Buntmergelserie), extends towards the west. The general dip of the Buntmergelserie towards the west, derived from the resistivity slices, might suggest this assumption. In such a case, groundwater could infiltrate the Buntmergelserie from below and hereby enhance the susceptibility to sliding at deeper layers.

The RFZ exhibits significantly higher resistivities, due to lower clay content implying a higher strength of the material. Therefore, only very shallow sliding events can be expected in this unit. Deep deformation processes are also hindered by the fact that very stable sandstone layers are available at the base of the sequence, which exhibit a higher resistance against rupture. Additionally, they are deeply tied inside the softer Buntmergelserie in the downslope western part. Thus, they represent a counter bearing for more incompetent material upslope. This could be the reason that so far hardly any larger mass wasting events took place in the Lidringbach valley.

An additional correlation was observed between the surface resistivity pattern, derived from multi-layer inversion results, and gamma-ray data. High resistivity often occurred in the zones of low thorium content, and reversely low resistivity well correlated with high thorium content. This is due to the fact that both parameters are related to the clay content.

To conclude based on the interpretation of the threedimensional subsurface resistivity distribution, the results from this test site show that the airborne electromagnetic method is well capable of resolving details about the general geological structure of the subsurface in landslide prone areas. Since this parameter mainly depends on water saturation and clay content, different susceptibilities towards sliding can be attributed to the derived structures, depending on their diverse electrical properties. However, due to the limited spatial resolution of the method and the low resistivity contrast within the recent mass movement, further results on the detailed internal structure of single landslide bodies could not be derived.
So far hardly any case studies are published concerning gamma ray surveys on landslides. However, since the respective nuclides can be found in different rocks and soils at various concentrations, the results from this study suggest that the spatial distribution of these elements and/or their ratio can provide information about soil parent material and soil and rock properties, such as composition, weathering, leaching clay types and others. This information could be used to determine areas with a higher susceptibility to sliding. Another interesting aspect is the mapping of ${ }^{137} \mathrm{Cs}$ distribution. Active landslide areas show lower ${ }^{137} \mathrm{Cs}$ activity due to surface water flows, increased soil erosion and covering of the topmost layer that lead to the migration of the nuclides.

\section{Discussion of the applicability of airborne geophysics for landslide mapping}

For improved landslide susceptibility and hazard zoning, there is a general need for input data with a good spatial coverage. The present study suggests that airborne geophysics is a promising method for landslide investigation and could provide such valuable additional information.

The big advantage of airborne geophysical measurements is that large areas can be surveyed within relatively short survey times. In fact, airborne electromagnetic is the only remote-sensing method which is able not only to survey near surface parameters but also to investigate geological structures below the ground surface down to several tens of metres.

Although the use of helicopters seems to be quite expensive, the method is very effective, since several sensor systems of different kind can be combined, which acquire all data at the same time and at the same location. If an equivalent amount of data had to be acquired on a comparably large area on the ground, the costs would be much higher as with airborne geophysics.

The application of airborne geophysics to landslides, however, has some limitations. As demonstrated by the present study, one major limit is terrain roughness: the ground clearance of the sensor needs to be below $90 \mathrm{~m}$, which is very difficult to be kept. Consequently, steep and rugged landscapes can only be surveyed under the following conditions: (i) well trained pilots for flying external cargo are needed, which are experienced in flying low altitude surveys; (ii) enough money is available to perform training flights with the system, to wait for optimum weather conditions and to repeat lines with bad data; and (iii) the engine of the helicopter needs to be strong enough (causing higher costs and a higher background noise level) to allow constant altitude flights in rough terrain.

To properly investigate landslide areas one also has to deviate from the conventional airborne survey routines. Traditionally, a research area is covered by parallel lines at a separation between 50 and $250 \mathrm{~m}$. However, for landslide mapping, smaller line spacings have to be favoured $(25-100 \mathrm{~m})$. 
Since in rugged terrains parallel lines cannot be easily maintained by the pilots at a maximum clearance of $90 \mathrm{~m}$, alternative schemes, like flying lines along topography at constant absolute altitude, have to be applied.

To evaluate in advance if airborne geophysics can effectively be applied, some additional facts have to be considered. Worldwide, the number of available multi-parameter systems is quite limited. Consequently, performing an airborne survey will require a significant time for planning in the forefront. Also legislative regulations for flying with external cargo might differ from country to country and very limiting security regulations are expected for the future.

Consequently, depending on local costs, this method might not be economically feasible for surveying small sites (e.g. below some $\mathrm{km}^{2}$ ). For such small-scale slides, the application of multi-electrode geoelectric surveys might be cheaper and provides a higher resolution.

Additionally airborne electromagnetic method is very sensitive to electromagnetic noise, caused, for example, by power lines and electrical cattle fences. For gamma measurements, delicate algorithms for correcting the influence of vegetation, soil humidity and topography are needed, which still need to be improved. For soil humidity measurements, algorithms for correcting the influence of vegetation are still not available.

Last but not least, calibration with ground geoelectrical measurements or other ground geophysical methods is highly recommended for proper interpretation of airborne electromagnetic results, which will cause additional costs.

\section{Conclusions}

The results from the Gschliefgraben test site suggest that ground resistivity, derived from AEM data, and soil moisture are effective parameters for investigating the local geological structure and for landslide susceptibility assessment and mapping. On the other hand, the distribution of potassium and thorium can be applied for reconstructing source areas of mass-movement deposits, identifying open joints and cracks in hard rock, fault zones in bedrock and/or the degree of chemical weathering.

Consequently, based on the results from this study and from Baroň et al. (2013) and Supper et al. (2008), we conclude that in general, airborne multi-parametric geophysics is a promising method, suitable

- for spatially delineating areas with a high susceptibility for future instabilities;

- to gain a better understanding of the regional geology in landslide prone areas; and

- for exploring the general structure of large landslides and deep-seated gravitational deformations.
On the contrary, ground geoelectric can be used to resolve the detailed internal structure of singular landslide bodies and to assess the dynamic subsurface situation by applying it in monitoring mode, both of which are beyond the limit of the spatial resolution of airborne geophysics.

High-resolution airborne geophysics however so far has only very rarely been applied to landslide investigations. The experiences, so far available, suggest some limiting factors and constraints for a successful application of this method for landslide investigation as described in the previous chapter. In particular, this demands that one has to deviate from traditional airborne survey procedures and adapt them to the special requirements of surveys in landslide prone areas. Therefore, for a more routine application to landslides, further investigations are needed to fully explore the potential of this method, to adopt the methodology to the special needs encountered with surveying landslide areas and to investigate the limitation of this approach in detail.

In regards to the local impact in the Gschliefgraben test site, the outcome from the airborne survey enabled a better understanding of the spatial and depth structure of the prevailing geological units. Thus the available model of the landslide and of related landslide processes was significantly improved, which helped to refine the design and define the proper location of sensors for an early warning network for the Gschliefgraben area.

Acknowledgements. The authors would like to acknowledge the excellent cooperation with the Austrian Service for Torrent and Avalanche Control (WLV), Section Upper Austria - especially to Wolfgang Gasperl and Harald Gruber - and with Centro Servizi di Geoingegneria, Ricaldone (Italy), and ZT Büro Moser/Jaritz, Gmunden (Austria). The geophysical measurements were supported by the project SafeLand "Living with the landslide risk in Europe: Assessment, effects of global change, and risk management strategies" under grant agreement no. 226479 in the 7th Framework Programme of the European Commission. Survey flights were performed in cooperation with the Austrian Army.

Edited by: S. Segoni

Reviewed by: four anonymous referees

\section{References}

Ahl, A. and Bieber, G.: Correction of the attenuation effect of vegetation on airborne gamma-ray spectrometry data using laser altimeter data, Near Surf. Geophys., 8, 271-278, 2010.

Avdeev, D. B., Kuvshinov, A. V., Pankratov, O. V., and Newman, G. A.: Three-dimensional frequency domain modelling of airborne electromagnetic responses, Explor. Geophys., 29, 111119, 1998.

Baroň, I., Supper, R., Winkler, E., Motschka, K., Ahl, A., Čarman, M., and Kumelj, Š.: Airborne geophysical survey of the catastrophic landslide at Stože, Log pod Mangrtom, as a test of an innovative approach for landslide mapping in steep 
alpine terrains, Nat. Hazards Earth Syst. Sci., 13, 2543-2550, doi:10.5194/nhess-13-2543-2013, 2013.

Egger, H. (Ed.): Geologische Karte der Republik Österreich 1:50 000, Blatt 66 Gmunden, Geologische Bundesanstalt Wien, 1996.

Egger, H. and van Husen, D. (Eds.): Geologische Karte der Republik Österreich 1:50 000, Blatt 67 Grünau im Almtal, Geologische Bundesanstalt Wien, 2007.

EM1DFM: A Program Library for Forward Modelling and Inversion of Frequency Domain Electromagnetic Data over 1D Structures, version 1.0. Developed by the UBC-Geophysical Inversion Facility, Department of Earth and Ocean Sciences, University of British Columbia, Vancouver, British Columbia, 2000.

Gondwe, B. R. N., Ottowitz, D., Supper, R., Motschka, K., MeredizAlonso, G., and Bauer-Gottwein, P.: Regional-scale airborne electromagnetic surveying of the Yucatan karst aquifer (Mexico): geological and hydrogeological interpretation, Hydrogeol. J., 20, 1407-1425, 2012.

IAEA-TECDOC-1363: Guidelines for radioelement mapping using gamma ray spectrometry data. International Atomic Energy Agency (IAEA), Nuclear Fuel Cycle and Materials Section, Austria, 2003.

Marschallinger, R., Eichkitz, C., Gruber, H., and Heibl, K.: The Gschliefgraben Landslide (Austria): A Remediation Approach involving Torrent and Avalanche Control, Geology, Geophysics, Geotechnics and Geoinformatics, Aust. J. Earth Sci., 102, 36-51, 2009.

Minty, B. R. S., Luyendyk, A. P. J., and Brodie, R. C.: Calibration and data processing for airborne gamma-ray spectroscopy, AGSO J. Aust. Geol. Geophys., 17, 51-62, 1997.

Moser, G.: Großhangbewegung Gschliefgraben - Fachübergreifender Synthese-Bericht, MS. Final report (in German). Moser/Jaritz and Wildbach und Lawinenverbauung, Gmunden, 329 pp., 2009.

Motschka, K.: Aerogeophysics in Austria, Bull. Geol. Surv. Jpn., 52, 83-88, 2001.

Nakazato, H. and Konishi, N.: Subsurface structure exploration of wide landslide area by Aerial electromagnetic exploration, Landslides (2005), 2, 165-169, 2005.

Nakazato, H., Kuroda, S., Okuyama, T., and Sasaki, Y.: The aim at a rich rural village utilizing water and soil. Improvement of production basis for improving productivity and exhibiting many-sided functions, and development of management techniques. Improvement of airborne electromagnetic method and three-dimensional resistivity distribution exploration in landslide areas. Mizu to Tsuchi o Ikashi Yutakana Noson o Mezashite Saishin Nogyo Kogaku Kenkyu Seikashu Heisei 18nen, 216217,2006
Pfaffhuber, A. A., Grimstad, E., Domaas, U., Auken, E., Foged, N., and Halkjær, M.: Airborne EM Mapping of rockslides and tunnelling hazards, The Leading Edge, 29, 936-939, 2010.

Prey, S.: Das Ultrahelvetikum-Fenster des Gschliefgrabens südöstlich von Gmunden (Oberösterrerich), Jb. Geol. B.-A., 126/1, 95-127, Vienna, 1983.

Rupp, C., Linner, M., and Mandl, W. (Red.): Erläuterungen zur Geologischen Karte von Oberösterreich, Verlag der Geologischen Bundesanstalt, Vienna, 2011.

Sasaki, Y. and Nakazato, H.: Inversion of airborne EM data accounting for terrain and inaccurate flight height, SEG Expanded Abstracts 23, 648-651, 2004.

Seiberl, W., Ahl, A., and Winkler, E.: Interpretation of airborne electromagnetic data with neural networks, Explor. Geophys., 29, 152-156, 1998.

Sengpiel, K. and Siemon, B.: Examples of 1-D inversion of multifrequency HEM data from 3-D resistivity distributions, Expl. Geophys., 29, 133-141, 1998.

Siehl, A.: Umweltradioaktivität, Ernst \& Sohn, Berlin, 1996.

Supper, R., Römer, A., Jochum, B., Bieber, G., and Jaritz, W.: A complex geo-scientific strategy for landslide hazard mitigation from airborne mapping to ground monitoring, Adv. Geosci., 14, 195-200, doi:10.5194/adgeo-14-195-2008, 2008.

Supper, R., Baron, I., Jochum, B., Ita, A., Winkler, E., Motschka, K., and Moser, G.: From structural investigation towards multiparameter early warning systems: geophysical contributions to hazard mitigation at the landslide of Gschliefgraben (Gmunden, Upper Austria), EGU2010-4649-1, Geophys. Res. Abstr. Vol. 12, 2010.

Tofani, V., Segoni, S., Agostini, A., Catani, F., and Casagli, N.: Technical Note: Use of remote sensing for landslide studies in Europe, Nat. Hazards Earth Syst. Sci., 13, 299-309, doi:10.5194/nhess-13-299-2013, 2013.

Thomson, S., Fountain, D., and Watts, T.: Airborne Geophysics - Evolution and Revolution, Proceedings of Exploration 07: Fifth Decennial International Conference on Mineral Exploration, edited by: Milkereit, B., 19-37, 2007,

Van Husen, D.: Die Ostalpen und ihr Vorland in der letzten Eiszeit (Würm), Karte 1:500 000, Geologische Bundesanstalt Wien, 1987.

Winkler, E., Seiberl, W., and Ahl, A.: Interpretation Of Airborne Electromagnetic Data with Neural Networks, in: Geophysical Applications of Artificial Neural Networks and Fuzzy Logic, edited by: Sandham, W. and Leggett M., Kluwer Academic Publishers, 2003. 